\title{
Asian summer monsoon anomalies induced by aerosol direct forcing - the role of the Tibetan Plateau
}

\author{
K. M. Lau ${ }^{1}$, M. K. Kim ${ }^{2}$ and K. M. Kim ${ }^{3}$ \\ ${ }^{1}$ Laboratory for Atmospheres, NASA Goddard Space Flight Center, Greenbelt, MD,USA \\ ${ }^{2}$ Department of Atmospheric Science, Kongju National University, Gongju, Korea \\ ${ }^{3}$ Science Systems and Applications, Inc., Lanham, MD, USA
}

Submitted to Climate Dynamics

July 2005 


\begin{abstract}
In this paper we present results of a numerical study using the NASA finite-volume GCM to elucidate a plausible mechanism for aerosol impact on the Asian summer monsoon involving interaction with physical processes over the Tibetan Plateau. . During the pre-monsoon season of March-April, dusts from the deserts of western China, Afghanistan/Pakistan, and the Middle East are transported into and stacked up against the northern and southern slopes of the Tibetan Plateau The absorption of solar radiation by dust heats up the elevated surface air over the slopes. On the southern slopes, the atmospheric heating is reinforced by black carbon from local emission. The heated air rises via dry convection, creating a positive temperature anomaly in the mid-to-upper troposphere over the Tibetan Plateaurelative to the region to the south. In May through early June in a manner akin to an "elevated heat pump", the rising hot air forced by the increasing heating in the upper troposphere, draws in warm and moist air over the Indian subcontinent, setting the stage for the onset of the South Asia summer monsoon. Our results suggest that increased dust loading coupled with black carbon emission from local sources in northern India during late spring may lead to an advance of the rainy periods and subsequent ly an intensification of the Indian summer monsoon The enhanced rainfall over India is associated with the development of an aerosolinduced large-scale sea level pressure anomaly pattern, which causes the East Asia $(M e i-y u)$ rain belt to shift northwestward, suppressing rainfall over East Asia and the adjacent oceanic regions .
\end{abstract}




\section{Introduction}

Recent studies have shown that aerosols can cause substantial alteration in the energy balance of the atmosphere and the earth surface, thus modulating the hydrologic cycle (Hansen et al. 2000; Jacobson 2001; Ramanathan et al.2001). In the Asian monsoon regions, aerosol is a major environmental hazard that is increasing at an alarming rate, and the monsoon water cycle is the lifeline to over $60 \%$ of the world's population. Yet the effects of aerosol and possible interactions with the monsoon dynamics remain largely unknown. Hence, a better understanding of interaction of aerosols on monsoon water cycle is paramount with huge science and society benefits. Numerical experiments from a general circulation model (GCM) have suggested that atmospheric circulation anomalies induced by black carbon from coal burning may be a cause of long-term drought over northern China, and excessive rainfall over southern China and India (Menon et al. 2002). Recently, Ramanathan et al (2005) shows that on climate change timescales, as a result of blocking of solar radiation reaching the surface by aerosol, i.e., global dimming, the earth surface cools, leading to a gradual spin-down of the tropical water cycle, and eventually weakening of the Asian monsoon. However on seasonal-to-interannual time scales, it is not clear how aerosols may impact the Asian monsoon. Absorbing aerosols such as dust and black carbon will heat the atmosphere due to shortwave absorption. Non-absorbing aerosols such as sulphate causes surface cooling by strongly scattering solar radiation, but have relatively little heating effects on the atmosphere itself. Overall, both absorbing and non-absorbing aerosols cool the earth surface by the global dimming effect. However, as we shall illustrate in this paper, for absorbing aerosols over elevated land with high surface 
albedo, in the presence of atmosphere and surface energy feedback, the effects may be quite different.

One of the key controls of the seasonalto-interannual variability of the Asian summer monsoon is associated with the reversal of meridional temperature gradient in the upper troposphere over the Tibetan Plateau (TP) and regions to the south in May and early June (Yanai et al. 1992; Meehl 1994; Li and Yanai 1996; Wu and Zhang 1998). The reversal is the result of rapid temperature rise due to surface heating over the TP, relative to the seasonal warming over the Indian Ocean. Here, we present results of GCM experiments, showing that aerosol-induced heating anomalies along the slopes of the TP may alter this key control, by accelerating and/or enhancing the temperature reversal in the upper troposphere during late boreal spring and early summer with strong impacts on the subsequent evolution of the Asian summer monsoon.

\section{Model basics}

We have conducted numerical experiments using the NASA finite volume atmospheric General Circulation Model (fvGCM) with Microphysics of Clouds in Relaxed Arakawa Schubert cumulus parameterization scheme (McRAS), and an improved radiative transfer code (Sud and Walker 1999a; Sud and Walker 1999b; Sud and Walker 2003; Chou and Suarez 1999; Chou et al. 2001). The ærosol optical thickness (AOT) of five aerosol species i.e., black carbon, organic carbon, soil dust, sulfate, and sea salt are obtained from three-dimensional monthly means for two years (2000-2001) from the Goddard Chemistry Aerosol Radiation and Transport (GOCART) model, which is driven by realistic global wind analyses. The GOCART aerosol distributions have been found to be in excellent agreement with satellite observations 
and sun photometer measurements globally and regionally (Chin et al. 2002; Chin et al. 2003). The extinction coefficient, single scattering albedo, and asymmetric factor of each aerosol type are obtained as functions of relative humidity and wave length of 11 spectral bands, based on Mie-theory calculations. The optical parameters of dust are considered as a function of wavelength only (Highwood et al 2003). The global aerosol radiative forcing used in this study, which includes seasonally varying horizontal and vertical distributions of different aerosol species transported by real wind, are far more realistic than that used in previous studies.

We have conducted a control and a basic anomaly experiment, with sea surface temperature (SST) prescribed from observed weekly mean data for 10 years from September 1987 to December 1996, and with all greenhouse gases (except water vapor) kept at prescribed present-day values. In the control experiment (NA), no aerosol forcing is included. The anomaly experiment (AA) includes radiative forcing from all aerosols types. We carry out additional model simulations, which are otherwise identical to AA, except for exclusion of black carbon (NB), of dust (ND), with dust only (DO) and with sulfate only (SO), to determine the role of different types of aerosols and to unravel the nonlinear nature of the interactions among forcing and responses (Kondratyev 1999).

\section{Results}

Figure la shows the time-latitude evolution of aerosol optical thickness (AOT) of carbonaceous (black carbon and organic carbon) and soil dust aerosols averaged over the longitude sector from India to the Takla makan desert $\left(65-95^{\circ} \mathrm{E}\right)$ from GOCART. In this region, the GOCART AOT of black carbon is about one-fifth of that of 
carbonaceous aerosol with a similar spatial pattern. Two branches of AOT can be identified - the southern branch over the Ganges Plain of northern India, along the southern slope of the TP and a northern branch on the northern slope of the TP. In the southern branch, carbonaceous aerosol is abundant beginning in late winter, and peaks in March and April. The sources are mostly from industrial pollution, as well as biomass burning over northwestern India and Pakistan. The carbonaceous aerosol is significantly reduced during the dry-to-wet transition period (May-June), due to the reduction of biomass burning, and wet deposition of airborne aerosols during the start of the wet season. Dust aerosols begin to build up over northern India in April-May, due to the increased transport of desert dust from the Middle East by low-level westerly flow from the Arabia Sea to India. In the northern branch, the aerosol consists primarily of dust transported from the Takla makan Desert $\left(40^{\circ} \mathrm{N}\right)$. Here, the dust loading builds up in March-April, peaks in May-June and declines towards the fall and winter. This distribution of absorbing aerosols is in agreement with observations from satellite derived aerosol optical thickness (not shown here, but will be reported in a separate paper).

\section{a. Temperature anomaly over the Tibetan Plateau}

In the following, we define an anomaly field as the mean difference between identical experiments with and without aerosol (AA-minus-NA) in the mean, averaged for ten seasons of the model integration. Figure 2 shows the surface air temperature anomaly patterns from March through June. Strong surface cooling is found in regions of heavy aerosol loading, i.e., carbonaceous aerosols over India, sulfate and black carbon over China, and soil dust over Afghanistan. This is due to the dimming effect, i.e., scattering and atmospheric absorption of solar radiation, reducing the amount reaching the earth 
surface. In June, the strong surface cooling in northern India may be associated with reflection of shortwave by increased high clouds from increased monsoon rain (see discussion for Fig. 6). In contrast to the surface cooling in surrounding regions, pronounced surface warming appears over and around the TP, especially in April and May (Fig. 2b and c). To understand the causes of the warming, Fig. 3 shows the height-latitude cross-section averaged along the longitude of the Indian subcontinent of AOT of dust and black carbon separately, and the total induced shortwave heating (shaded). It is clear that the shortwave heating is strongly tied to the concentration of black carbon (dotted contour) and dust (solid contour). The most pronounced shortwave heating is found in the lower troposphere, but over and around the TP, the heating effect extends to the mid-and upper troposphere. In March-April (Fig.3a and b), the shortwave heating is concentrated over northern India, where the black carbon is abundant. In April-through-June (Fig.3c and d) the shortwave heating is strongest on the southern and northern slopes of the TP, due to the accumulation of dust aerosols. As the mid-tropospheric over the elevated slopes of the TP, the near surface warm air is forced to rise by dry convection, a positive upper tropospheric temperature anomaly emerges over the TP in March-April (Fig 4a and b). In April, closely tied to the shortwave heating and the aerosol loading patterns, two branches of induced rising motions are clearly visible over the southern and northern slopes of the Plateau (Fig 4b). In May, the warming in the upper troposphere becomes fully development, while the southern ascending branch strengthens, and the northern branch weakens (Fig. 4c). The forced ascent acts as an "elevated heat pump", drawing in more moist warm air from below, accelerating the warming, and increas ing convective available potential energy, as the monsoon season approaches. At this time, the ascent has reached the lower 
levels of the atmosphere, and intensified With a well-defined subsiding branch over the region to the south $\left(0-10^{\circ} \mathrm{N}\right)$. In June, the anomalous ascent intensifies due to increased latent heating (see also Fig.6), shifts southward to northern India $\left(20^{\circ} \mathrm{N}\right)$, and induces strong subsidence over the southern part of the Indian subcontinent and the northern Indian Ocean, establishing a well-defined reversed anomalous meridional overturning. At this time, the Indian monsoon is well established, and black carbon loading is diminished, but dust aerosols transported by low level westerlies (not shown) across the Arabian Sea continues to provide anomalous aerosol forcing over northern India.

The aerosol-induced large-scale differential heating/cooling of the atmosphere-land region over the $\operatorname{TP}\left(70-100^{\circ} \mathrm{E}, 25-40^{\circ} \mathrm{N}\right)$, and region to the south $(\mathrm{RS})\left(70-100^{\circ} \mathrm{E}, 10-\right.$ $25^{\circ} \mathrm{N}$ ) is further illustrated by examining the anomalies in heat fluxes at the surface and the top of the atmosphere over these regions (Table 1). Note that the TP consists of mostly elevated, high-albedo land surface, and RS has generally darker surface consisting of vegetated land and dark oceans. For both regions, the anomalous fluxes are much larger at the surface and in the interior of the atmosphere than at the top of the atmosphere (TOA), because of the strong compensation between longwave and shortwave effects at the TOA. Over the TP, the anomalous heating of the atmosphere by shortwave absorption $\left(16.8 \mathrm{Wm}^{-2}\right)$ is substantially stronger than that $\left(14.3 \mathrm{Wm}^{-2}\right)$ in $\mathrm{RS}$, due to the stronger absorption from multiple reflections between the aerosol layer and the high-albedo land surface. While the surface energy loss by shortwave over TP is stronger $\left(-21.3 \mathrm{Wm}^{-2}\right)$ compared to $\mathrm{RS}\left(-19.8 \mathrm{Wm}^{-2}\right)$, the loss is compensated by stronger longwave downward emission $\left(8.7\right.$ vs. $\left.6.1 \mathrm{Wm}^{-2}\right)$. The largest difference between TP and RS is the strong sensible heating of the surface $\left(12.4 \mathrm{Wm}^{-2}\right)$ from the 
warmer atmosphere over the TP, compared to $\mathrm{RS}\left(6.7 \mathrm{Wm}^{-2}\right)$. Latent heat has negligible contribution in TP, because April-May is before the rainy season there. Over $\mathrm{RS}$, latent heat flux plays a stronger role than that over TP, but is still modest compared to the radiative and sensible heat fluxes. Over TP, the atmosphere-land system is nearly in balance with a small residual heating term $\left(0.2 \mathrm{Wm}^{-2}\right)$. In contrast, over RS, there is a net cooling of the surface of $-3.7 \mathrm{Wm}^{-2}$, because oceanic regions with prescribed SST are included. Note that these numbers should be considered only relative in the context of the model experiments, and should not be viewed as actual simulation of realistic events. To compare with observations, they need to be scaled with variability and trends of aerosols on different time scales, which is outside the scope of this work.

\section{b. Aerosotinduced Monsoon Variability}

Figure 5a and b show the time-latitude section of upper troposphere $(500 \mathrm{hPa}$ to the tropopause) shortwave heating and temperature anomalies over the longitude sector of the Indian subcontinent $\left(70-100^{\circ} \mathrm{E}\right)$. Here, as shown previously, the upper troposphere is heated by absorbing aerosols, i.e., dust and black carbon, in addition to vertical advection by dry convection over the elevated surface. Maximum upper tropospheric temperature anomaly appears over the TP in May. Concomitant with the temperature anomaly is the strengthening of the upper tropospheric anticyclonic circulation over the $\mathrm{TP}$, and surface westerlies over the Indian subcontinent in May (not shown), signalling an advance of the monsoon season. Figure $5 \mathrm{c}$ and $5 \mathrm{~d}$ show the time-latitude sections of vertically integrated troposphere shortwave heating and precipitation anomaly over the India region $\left(65-95^{\circ} \mathrm{E}\right)$, respectively. Two separate heating maxima are found over northern and southern sides of the TP, which are quite distinct from the upper troposphere heating pattern shown in Fig. 5a. The similarity of the low-to-mid 
tropospheric shortwave heating variation to that of AOT shown in Fig. 1 provides further evidence of the importance of heating by absorbing aerosols. The difference between the vertically integrated (Fig. 5c) and the upper troposphere (Fig. 5a) atmospheric heating anomalies underscores the importance of direct aerosol heating below $500 \mathrm{hPa}$, and illustrates the unique role of the surface and atmospheric processes over the TP, as discussed previously, in regulating the response of the monsoon climate to aerosol forcing. Fig. 5c also illustrate that although the optical thickness of carbonaceous aerosol is significantly reduced from May to June, atmospheric heating, mainly due to dust, is still significant over northern India.

As a result of the aerosol induced upper troposphere warming over the TP, and the lower-level heating and forced ascent over northern India, significant increase in rainfall over northern India $\left(20^{\circ} \mathrm{N}\right)$ is found in May, suggesting an advance of the monsoon rainy season (Fig. 5d). The increased rainfall over northern India continues through the entire summer season, June through August (JJA), while rainfall is suppressed to the south. As evident in the JJA rainfall anomaly pattern shown in Fig. 6a, the excessive monsoon rainfall is concentrated over northwestern India and the Bay of Bengal, while rainfall is suppressed over the northern Indian Ocean, East Asia and the western Pacific. The rainfall pattern is associated with the establishment of a surface pressure dipole, comprising of a heat low over the interior of Asia centered over the TP, and an elongated southwest-northeast oriented high pressure ridge extending from the northwestern Pacific and the northern South China Sea, to the southern Bay of Bengal and the central Indian Ocean (Fig. 6b). The high pressure ridge amounts to an eastward extension of the western Pacific Subtropical High, causing the East Asia (Mei-yu) rain belt to weaken and shift northward and northwestward inland (Chang et al. 2000; Lau 
and Li 1984). This finding is also in agreement with the previous study indicating that anomalous heating over the TP may cause a northward shift of the Mei-yu (Chou 2003). The intensified Indian monsoon is clearly seen in the increased $850 \mathrm{hPa}$ westerly wind anomalies and cyclonic flow over northern India (Fig. 6b). The westerly wind flow turns southwesterly over northern Indo-China and central East Asia, through northeastern China to northern Japan, as part of the anticyclonic flow around the northern flank of the anomalous high pressure ridge over the western Pacific. On the southern flank of the anticyclone, anomalous northeasterly wind prevails over northern South China Sea and easterlies over equatorial Indian Ocean. The anomaly wind pattern over East Asia and the western Pacific is indicative of a weake ning of the East Asian monsoon(Liu and Wu 2004; Wang and Lin 2002).

\section{c. Model sensitivity to aerosol types}

To isolate the effects of different aerosol types, and to test the robustness of our results, we have repeated the anomaly experiment with various combination of aerosol forcing. Figure 7 shows the JJA rainfall anomaly patterns and associated statistical significance level for selected combination of aerosol forcing. For example, Figs. 7b, and $\mathrm{c}$, which shows the rainfall anomaly defined by AA-minus-ND, and AA-minus-NB respectively is equivalent to the effect of dust-only and black carbon-only relative to AA. Figure 7d (AA-minus-SO) can be identified with effect of all other aerosols (mainly from dust and carbonaceous aerosol), except sulfate. All cases depict positive rainfall anomalies over wrthern India and general reduction of rainfall over the East Asian continent and adjacent oceans. In Fig. 7a, as indicated by the pattern of statistical significance, the rainfall anomalies induced by AA, over northern India and Bay of Bengal, and northern Indian Ocean are very robust, while anomalies over East 
Asia are less so. As evident in Fig. 7b, desert dust plays a key role in rainfall enhancement over central Asia, and suppression over East Asia/western Pacific. Fig. 7c shows that black carbon is instrumental in initiating the regional rainfall anomalies over northern India, through induced low level heating and forced upward motion as previously discussed in relation to Fig. 3 and Fig. 4, but not enough on its own to produce statistically significant signals over the large-scale monsoon regions. Most important, the similarity of Fig. 7a and $7 d$ suggests that sulfate aerosol while adding details and complexity to the overall rainfall anomaly pattern, has the least impact on the rainfall anomalies over the entire monsoon region.

Additional analyses have been carried out to determine the internal model variability compared to the response for different scenarios of aerosol forcing. The internal variability is computed as the interannual variability of the no-aerosol (NA) run, which also include SST anomalous forcing. Fig. 8 shows the mean model simulated precipitation over all India, for all previously-described model experiments, as a function of the calendar month. The internal variability computed as the $95 \%$ significance level from NA, is shown as the vertical width of the shaded region. The internal variability is relatively small from January through May, compared to June through October. The aerosol signals rises above the internal variability including those due to SST forcing in May through July, but not the other months. The response is most robust for the all-aerosol (AA) experiment, with an emerging signal that begins in April and rises well above the noise level in May, June and July. June appears to be the month that is most sensitive to various aerosol forcing scenarios, including no-black carbon (NB), no-dust (ND), dust-only (DO), confirming the conclusion that the combination of dust and black carbon are important in contributing to monsoon 
variability. Of all the aerosol forcing scenarios, the sulfate-only (SO) case seems to produce negligible impacts on monsoon variability. This is because sulfate aerosol is non-absorbing, and does not directly lead to atmospheric heating.

The above results imply that dust and black carbon each contributes to the monsoon rainfall anomaly in important ways, with the former playing the primary role. However, it is the combined effect of these absorbing aerosols that are critical in initiating and maintaining the monsoon rainfall and large-scale circulation anomalies. Absorbing aerosols, because of its ability to heat the atmosphere, and change static stability and convective potentials are more effective in redistributing atmospheric heat sources and sinks and therefore generate monsoon anomalies. Scattering aerosols, e.g., sulfate, on the other hand, can also contribute to monsoon variability but more so indirectly and likely on longer time scales, through cooling of the land surface and subsequent feedback processes involving the monsoon water cycles, and large scale dynamics (Lau and Bua 1998).

\section{Concluding Remarks}

From GCM experiments, we find that anomalous atmospheric heating by absorbing aerosols can cause an advance and subsequent intensification of the Indian monsoon with enhanced rainfall anomaly over northern India and the Bay of Bengal. The monsoon advance is due to the accelerated heating in the upper troposphere over the TP in April-May induced by absorbing aerosok, mainly black carbon and dust over the southern and northern slopes of the TP. As the warm air rises, the upper troposphere warm anomaly acts as a "elevated heat pump" that draws in warm moist air from below, leading to forced ascent, and enhanced convection, and increased summer 
monsoon rainfall over northern India. This effect is consistent with many previous studies indicating the important of raidative and sensible heat flux over the TP in affecting the subsequent evolution of the Asian summer monsoon (Wu and Zhang 1998; Wu et al. 1997; Li and Yanai 1996). The intensification of the Indian monsoon is a part of a large -scale circulation anomaly associated with a dipole sea level pressure anomaly pattern consisting of a heat low over the interior of Asia, and an extended subtropical high from the western Pacific to the Indian Ocean, induced primarily by absorbing aerosols, i.e., dust and black carbon. The pressure dipole anomaly enhances the Indian monsoon by strengthening the low level westerly flow over central and northern Indian, but weakens the southwesterly monsoon over South China, thereby shifting the Mei-yu rain belt northwestward, and suppressing rainfall over East Asia and adjacent oceanic regions.

Since the paper represents a first-of-the-kind attempt in using a GCM, combined with realistic, 4-dimensional global aerosol forcing derived from global chemistry transport model to study the climatic impact of aerosol on monsoon water cycle, it is important to keep in mind the various limitations, and caveats when interpreting the model results. First, since the experiments are designed to identify plausible critical pathways in which absorbing aerosols may affect and interact with the atmospheric-land water cycle, the interaction with sea surface temperature is held back in these experiments. Because natural dust loading is strongly linked to the monsoon large scale circulation, the mechanism identified here may be more applicable for intraseasonalto-interannal, but not necessarily climate change ( $>$ decadal) time scales, where interactive SST has to be included. Hence, the magnitude of the anomalies in the present calculation should not be taken literally, because for ease of process 
identification, we only consider binary changes ( 0 or $100 \%)$ in different aerosol types. To compare with observations, the magnitudes of the anomalies need to be scaled with the variability of different species of aerosols on different time scales. Alternatively, additional experiments need to be carried out using realistic estimates of variability of different types of aerosols, but such estimates are difficult to obtain at present, and will need much better global observations of aerosols characteristics. Thus the present results should be considered qualitatively and only as a working hypothesis for aerosol effects on monsoon water cycle. Validation of this working hypothesis is being carried out with additional experiments and available observations, and will be reported in a separate paper.

Second, only direct effects of aerosols have been included in this study. Indirect (microphysical) effects of aerosols on clouds and precipitation will most likely further complicated matters. Indirect effects of aerosols are still a subject of intense research, and not yet ready to be implemented realistically in global models. We note that even for direct effects, there is considerable uncertainty regarding the absorptivity of dust over the South Asian monsoon region. Here, for lack of aerosol data over India, we have used the standard values from the GOCART model, which has been calibrated using data from the Aerosol Characterization Experiments over Asia (ACE-Asia), in the East Asian region. Most important, our results emphasize the importance of atmospheric water cycle dynamics and surface energy feedback triggered by aerosol direct effects. It is our opinion that it is not so much the absorptivity per unit aerosol, but the expansive span and depth of the aerosol layer, in particular dusts that are lofted into the mid- and upper troposphere by wind, and stacked up against the slopes of the Tibetan Plateau, 
that are critical in producing the "elevated heat pump" effect, which subsequently redistribute heat sources and sinks in the monsoon region.

Third, another major limitation of this study is that although the water cycle is allowed to interact with effects caused by aerosols including clouds and radiation, and the relative humidity dependence is built into the radiative properties of the different types of aerosols, the aerosol concentrations themselves are not interactive with atmospheric dynamics, but are prescribed from the GOCART model outputs. Additionally aerosol-aerosol interactions, such as coating of dusts by industrial pollution, e.g., sulfate and black carbon, which changes the radiative properties of the incipient aerosol, have not been included.

Finally, we fully recognized that in reality, the aerosol impact mechanism illustrated here will be confounded by interactive sea surface temperature such as El Niño and La Niña, snow cover changes and global warming, and/or dimming effects, as well as aerosol chemical effects. Hence, this work is just a starting point of a new challenge to monsoon water cycle research and it serves only as a prelude to further model experiments with coupled atmosphere-ocean-land GCMs, including interactive aerosol, chemistry and large scale dynamics, and validations with observations.

Acknowledgement This work is supported jointly by the Modelling, Analysis and Prediction (MAP) Program, and the Precipitation Measuring Mission (PMM) of the NASA Earth-Sun Exploration Division. M. K. Kim is supported by Climate Environment System Research Center (CES) sponsored by the Korea Science and Engineering Foundation. Part of the work was carried out by M. K. Kim during his visit 
to the Laboratory for Atmospheres, Goddard Space Flight Center under a Goddard Earth System Technology (GEST) visiting fellowship. 


\section{References}

Chang CP, Zhang YS, Li T (2000) Interannual and interdecadal variations of the East Asian summer monsoon and tropical SSTs. Part I: Role of the subtropical ridge. J Climate 13:4310-4325

Chin M, Ginoux P, Kinne S, Torres O, Holben BN, Duncan BN, Martin RV, Logan JA, Higurashi A, Nakajima T (2002) Tropospheric Aerosol Optical Thickness from the GOCART Model and Comparisons with satellite and Sun photometer Measurements, J Atmos Sci 59: 461-483

Chin M, Ginoux P, Lucchesi R, Huebert B, Weber R, Anderson T, Masonis S, Blomquist B, Bandy A, Thornton D (2003) A global aerosol model forecast for the ACE-Asia field experiment. J Geophys Res 108(D23): 8654 DOI 10.1029/2003JD003642

Chou C (2003) Land-sea heating contrasts in an idealized Asian summer monsoon. Clim Dyn 21: 11-25

Chou MD, Suarez M (1999) A solar radiation parameterization for atmospheric studies. Tech RepNASA/TM-1999-104606, NASA/GSFC

Chou MD, Suarez M, Liang XZ, Yan MH (2001) A thermal infrared radiation parameterization for atmospheric studies. Tech Rep NASA/TM-2001-104606, NASA/GSFC

Hansen J, Sato M, Ruedy R, Lacis A, Oinas V (2000) Global warming in the twentyfirst century: an alternative scenario. Proc Natl Acad Sci 97: 9875-9880

Highwood EJ, Haywood J, Silverstone M, Newman S, Taylor J (2003) Radiative properties and direct effect of Saharan dust measured by the C-130 aircraft during SHADE-2: Terrestrial spectrum. J Geophys Res 108(D18): 8578, DOI 10.1029/2002JD002552

Jaconbson MZ (2001) Strong radiative heating due to the mixing state of black carbon in atmospheric aerosols. Nature 409: 695-698

Kondratyev KY (1999) Climatic effects of aerosols and clouds . Praxis Publishing, UK, $264 \mathrm{pp}$ 
Lau KM, Bua W (1998) Mechanisms of monsoon-Walker circulation: Insights from GCM experiments. Clim Dyn 14: 759-779

Lau KM, Li MT (1984) The monsoon of East Asia and its global associations - A survey. Bull Amer Meteor Soc 65: 114-125

Li C, Yanai M (1996) The onset and interannual variability of the Asian summer monsoon in relation to land-sea thermal contrast. J Climate 9: 358-375

Liu YM, Wu G (2004) Progress in the study on the formation of the summertime subtropical anticyclone. Adv Atmos Sci 21: 422-342

Meehl GA (1994) Coupled land-ocean-atmosphere processes and South Asian monsoon variability. Science 266: 263-267

Menon S, Hansen J, Nazarenko L, Luo Y (2002) Climate effects of black carbon aerosols in China and India. Science 297: 2250-2253

Ramanathan V, Chung C, Kim D, Bettge T, Buja L, Kiehl JT, Washington WM, Fu Q, Sikka DR, Wild M (2005) Atmospheric brown clouds: impact on South Asian climate and hydrologic cycle. Proc Natl Acad Sci 102: 5326-5333, DOI 10.1073/pnas.0500656102

Ramanathan V, Crutzen PJ, Kiehl TJ, Rosenfeld D (2001) Aerosols, climate and the hydrological cycle. Science 294: 2119-2124

Sud YC, Walker GK (1999a) Microphysics of clouds with the relaxed ArakawaSchubert scheme (McRAS). Part I: Design and evaluation with GATE phase III data. J Atmos Sci 56: 3196-3220

Sud YC, Walker GK (1999b) Microphysics of clouds with the relaxed ArakawaSchubert scheme (McRAS). Part II: Implementation and performance in GEOS II GCM. J Atmos Sci56: 3221-3240

Sud YC, Walker GK (2003) New upgrades to the microphysics and thermodynamics of clouds in McRAS: SCM and GCM evaluation of simulation biases in GEOS GCM. Proc Indian Natn Sci Acad 69(5): 543-565.

Wang B, Lin H (2002) Rainy season of the Asian-Pacific summer monsoon. J Climate 5: $386-398$

Wu G, Zhang XH (1998) Tibetan Plateau forcing and the timing of the monsoon onset over South Asia and the South China Sea. Mon Wea Rev 126: 913-927 
Wu G, Li WP, Guo H, Liu H (1997): Sensible heating-drive air pump of the Tibetan Plateau and the Asian summer monsoon. In: Ye DZ (ed) Memorial Volume of Prof. JZ Zhao. Sci. Press, Beijing, pp16-126

Yanai M, Li C, Song Z (1992): Seasonal heating of the Tibetan Plateau and its effects on the evolution of the Asian summer monsoon. J Meteor Soc Japan 70: 189-221 
Table 1 Aerosol induced change in surface heat fluxes of shortwave (SW), longwave (LW), sensible heat $(\mathrm{SH})$ and latent heat $(\mathrm{LH})$ of the atmosphere-land region over the $\mathrm{TP}(60-$ $\left.120^{\circ} \mathrm{E}, 25-40^{\circ} \mathrm{N}\right)$ and the RS $\left(60-120^{\circ} \mathrm{E}, 10-25^{\circ} \mathrm{N}\right)$, at the top of the atmosphere (TOV), the atmospheric column (ATM), and at the surface (SFC).

\begin{tabular}{|c|c|c|c|c|c|c|c|c|c|c|}
\hline & \multicolumn{5}{|c|}{$\mathrm{TP}\left(60-120^{\circ} \mathrm{E}, 25-40^{\circ} \mathrm{N}\right)$} & \multicolumn{5}{|c|}{$\operatorname{RS}\left(60-120^{\circ} \mathrm{E}, 10-25^{\circ} \mathrm{N}\right)$} \\
\hline & SW & $\mathrm{LW}$ & $\mathrm{SH}$ & $\mathrm{LH}$ & Net & SW & LW & $\mathrm{SH}$ & $\mathrm{LH}$ & Net \\
\hline TOA & -4.5 & 2.9 & - & - & -1.6 & -5.5 & 4.5 & - & - & -1.0 \\
\hline ATM & 16.8 & -5.8 & -12.4 & -0.4 & -1.8 & 14.3 & -1.6 & -6.7 & -3.3 & 2.7 \\
\hline $\mathrm{SFC}$ & -21.3 & 8.7 & 12.4 & 0.4 & 0.2 & -19.8 & 6.1 & 6.7 & 3.3 & -3.7 \\
\hline
\end{tabular}




\section{Figure Captions}

Figure 1. Time-latitude distributions of (a) aerosol optical thickness of soil dust (solid line) and carbonaceous (short-dashed line) aerosols over Indian summer monsoon longitude sector $\left(65-95^{\circ} \mathrm{E}\right)$, derived from the GOCART model, with total aerosol optical thickness over 0.15 shaded.

Figure 2 Surface air temperature anomalies induced by aerosols (AA-minus-NA) over the Asian monsoon region for (a) March, (b) April, (c) May, and (d) June. Contour intervals are $0.5^{\circ} \mathrm{K}$. Positive anomalies are shaded.

Figure 3 Latitude-height distributions of aerosol optical thickness of dust (solid contour), black carbon (dotted contour) and shortwave heating (shaded) over the bngitude sector of $70-100^{\circ} \mathrm{E}$ for (a) March, (b) April, (c) May and (d) June. Contour interval of aerosol optical thickness is $2 \times 10^{-3}$ for dust and $1 \times 10^{-3}$ for black carbon. Contour interval of shortwave heating rate is $0.1^{\circ} \mathrm{C}$ per day.

Figure 4. Same as in Fig. 3 except for distributions of temperature and meridional circulation anomalies due to aerosols for (a) March, (b) April, (c) May, and (d) June. Units of pressure velocity and meridional wind are $-10^{-4} \mathrm{hPa} \mathrm{s}^{-1}$ and $\mathrm{ms}^{-1}$, respectively. Contour intervals are $0.5 \mathrm{~K}$. Temperature anomalies over $0.5 \mathrm{~K}$ are shaded.

Figure 5. Time-latitude distributions of monthly anomalies due to aerosols averaged over longitudinal sector of $65^{\circ}-95^{\circ} \mathrm{E}$ for (a) vertically integrated upper level shortwave heating $\left(\mathrm{Wm}^{-2}\right)$ from $500 \mathrm{hPa}$ to the tropopause, (b) upper- tropospheremean temperature $(500-200 \mathrm{hPa})$, (c) vertically integrated troposphere shortwave heating $\left(\mathrm{Wm}^{-2}\right)$, and (d) precipitation $\left(\mathrm{mm} \mathrm{day}^{-1}\right)$.

Figure 6. Spatial distribution of JJA anomalies in the Asian monsoon region due to aerosols for (a) precipitation ( $\left.\mathrm{mm}_{\text {day }}{ }^{-1}\right)$, and (b) sea level pressure (hPa) and 850 $\mathrm{hPa}$ winds $\left(\mathrm{ms}^{-1}\right)$. 
Figure 7. Spatial patterns of JJA precipitation anomalies $\left(\mathrm{mm} \mathrm{day}^{-1}\right)$ due to (a) all aerosols (AA-minus-NA), (b) dust (AA-minus-ND), (c) black carbon (AA-minusNB), and (d) all aerosols except sulfate (AA minus SO). Negative rainfall anomalies are shaded. Grid points with statistical confidence level exceeding $10 \%$ and $5 \%$ are indicated by small and large close circles.

Figure 8 Annual cycle of model simulated monthly precipitation $\left(\mathrm{mm} \mathrm{day}^{-1}\right)$ over northern India $\left(70-90^{\circ} \mathrm{E}, 20-30^{\circ} \mathrm{N}\right)$ for various aerosol forcing experiments, i.e., non-aerosol (NA), allaerosol (AA), no-black carbon (NB), no-dust (ND), dust-only (DO), and sulfate-only (SO). Model internal variability, computed as the $95 \%$ confidence levelfor NA is shown as the width of the shaded region. 


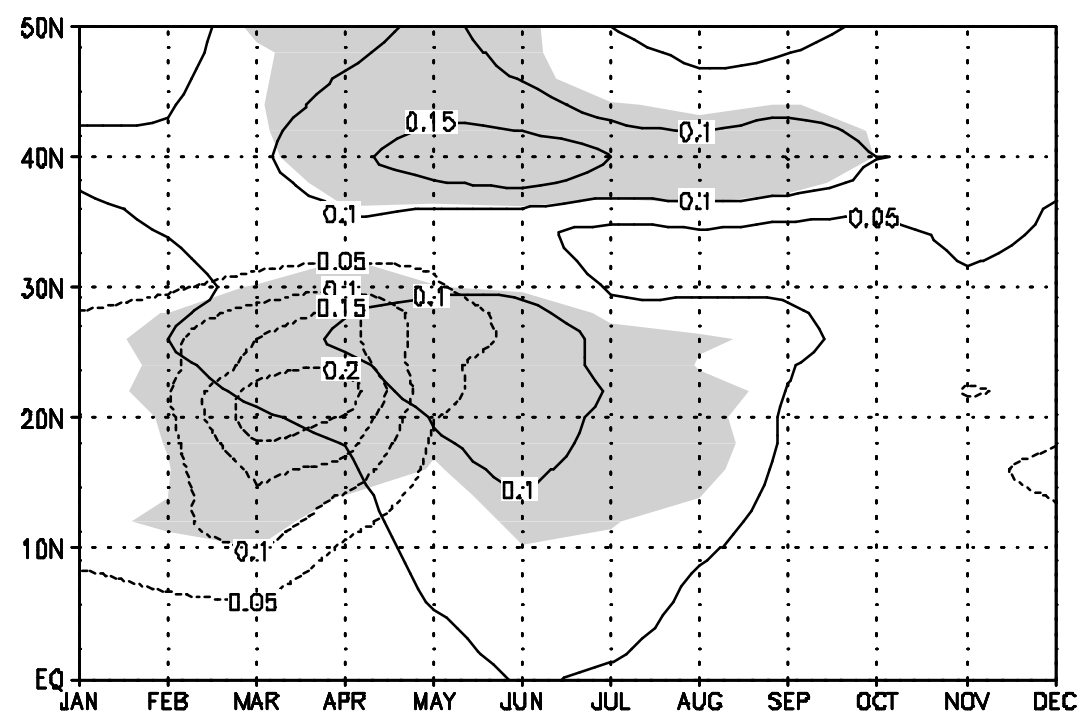

Fig. 1 

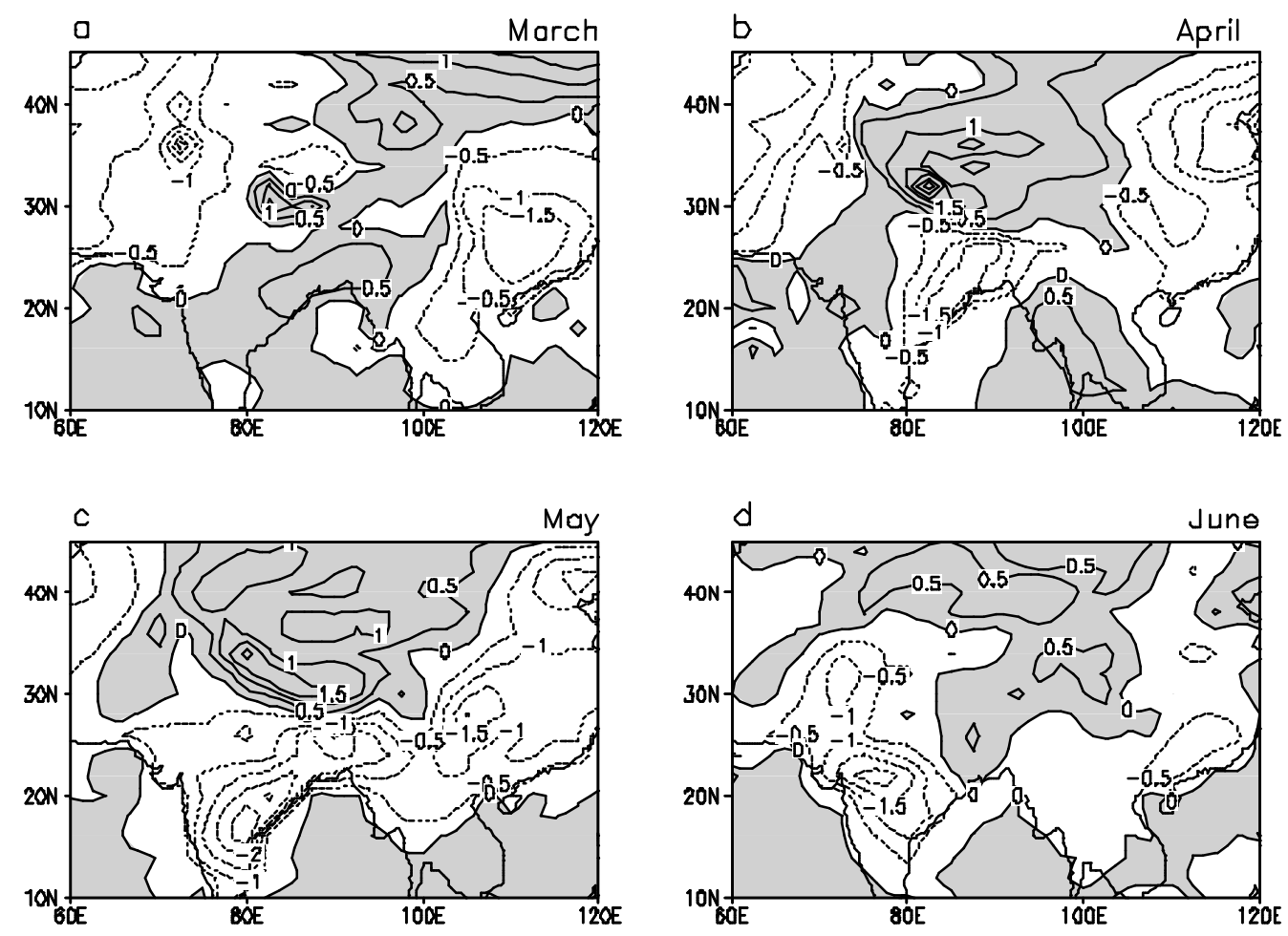

Fig. 2 

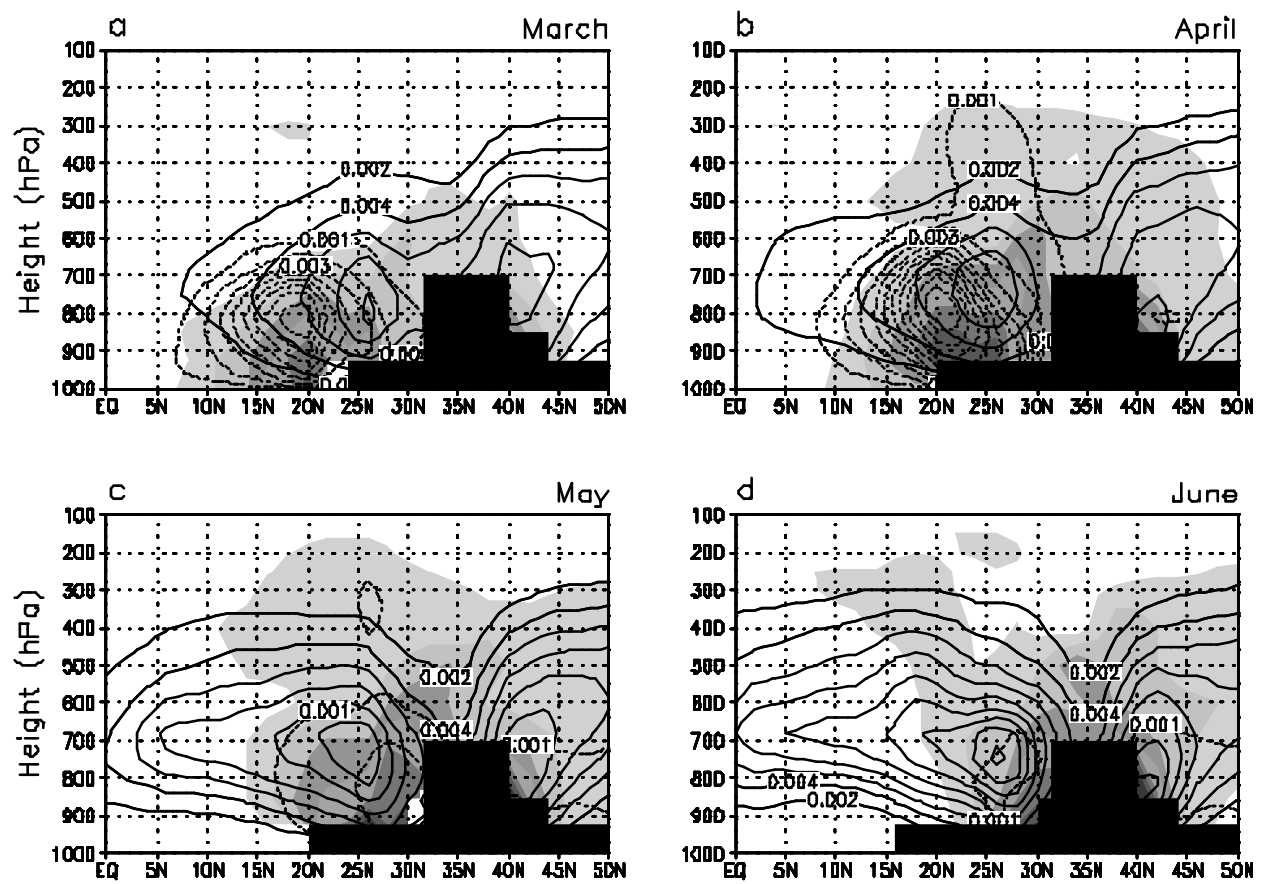

Fig. 3 

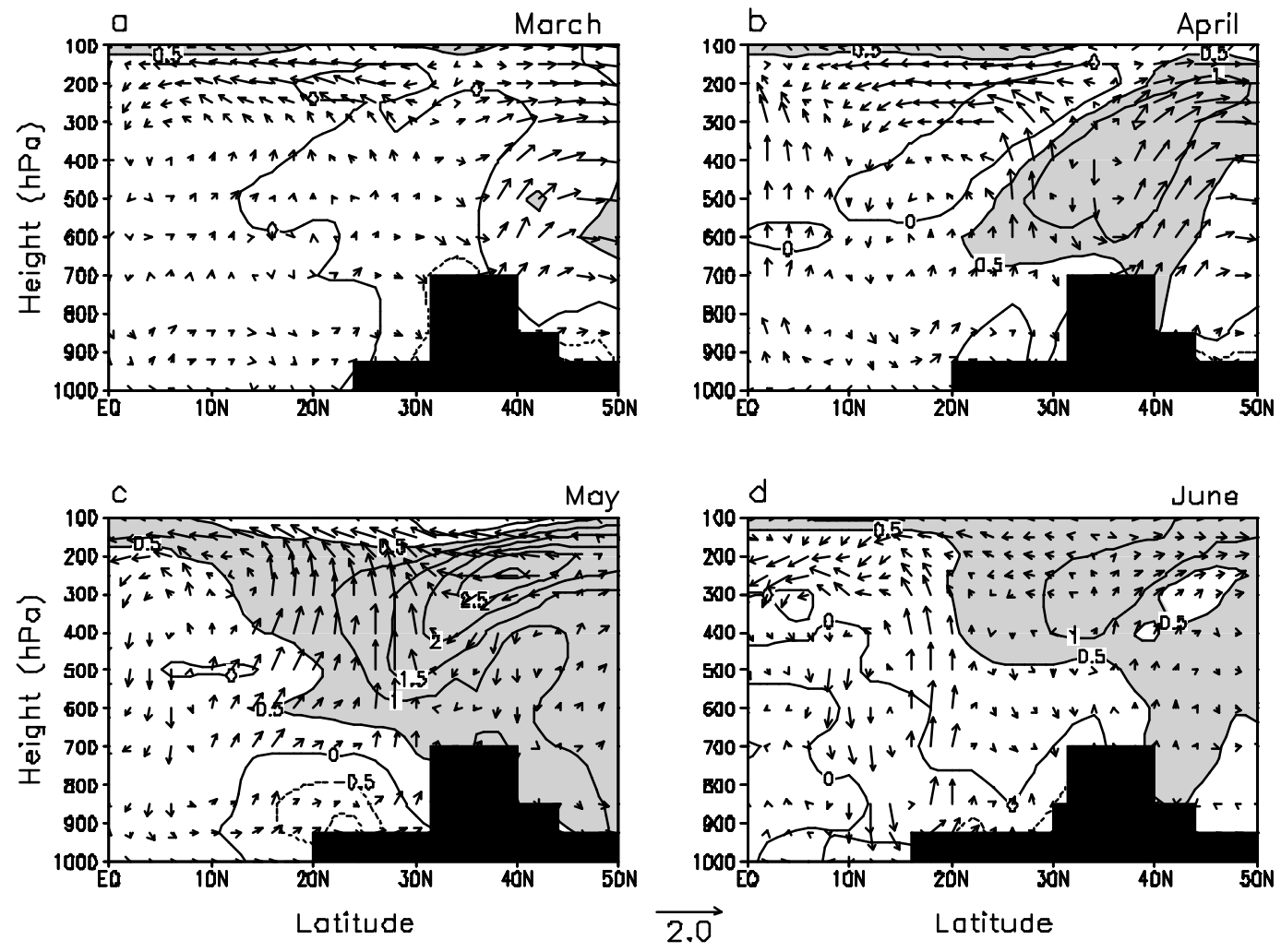

Fig. 4 

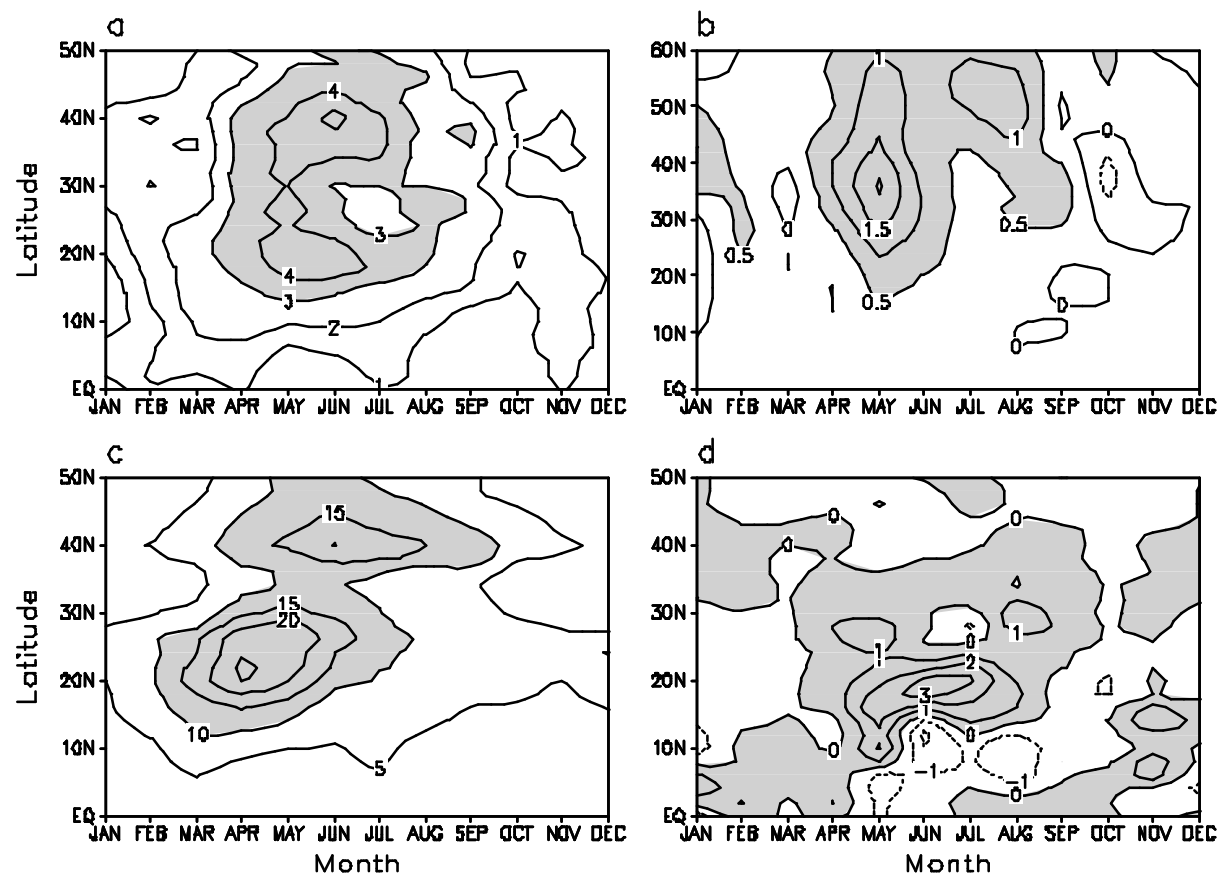

Fig. 5 

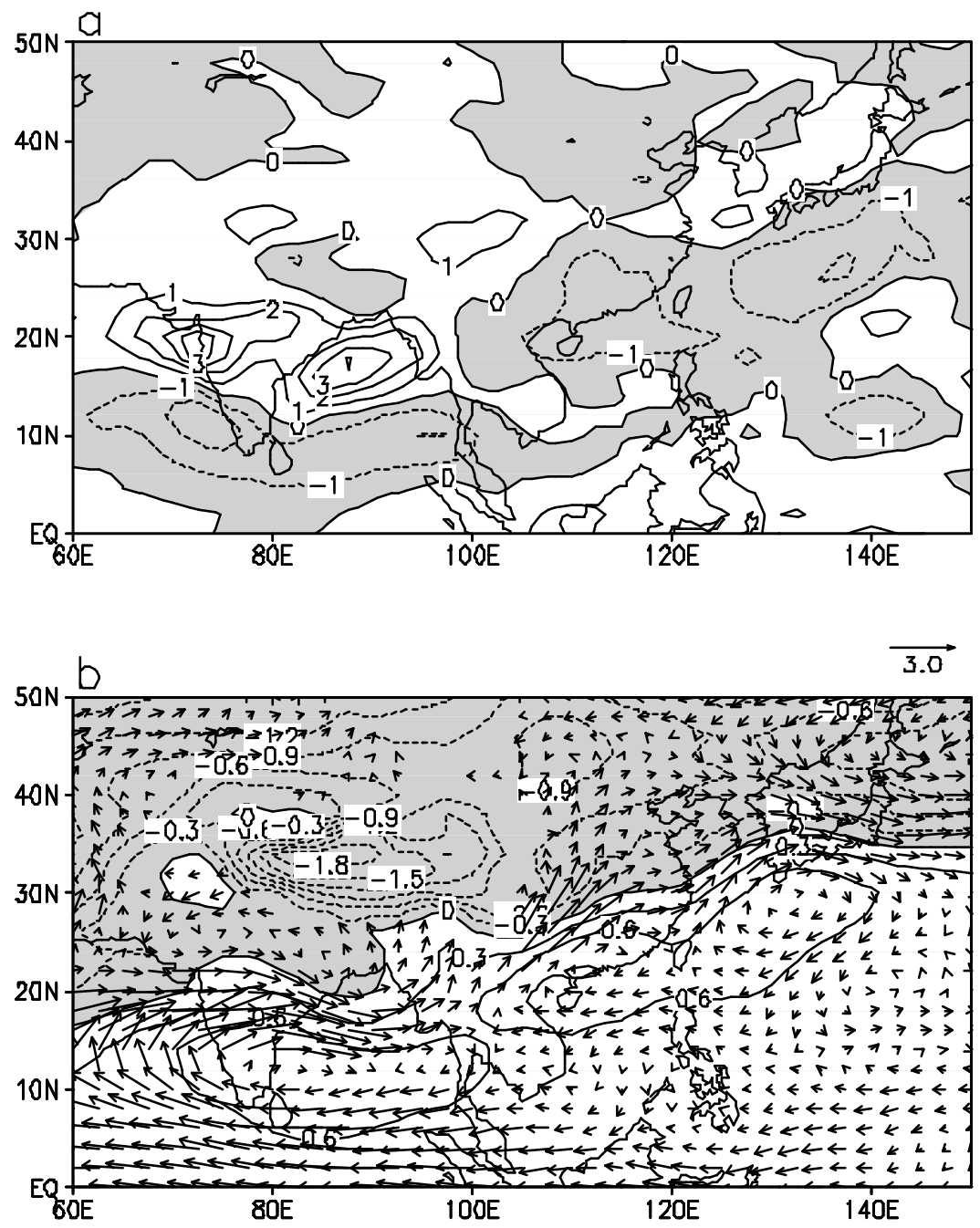

Fig. 6 

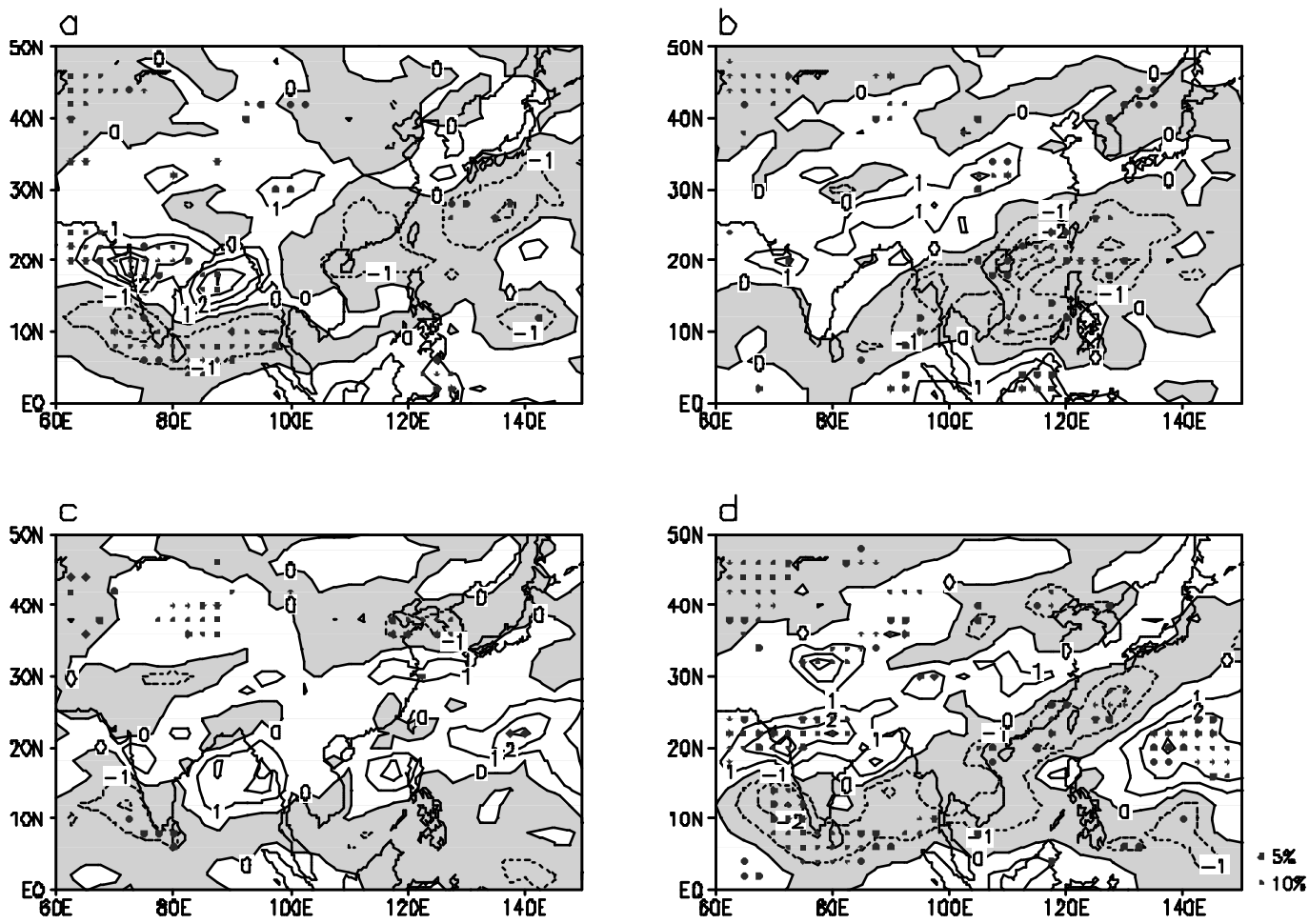

Fig. 7 


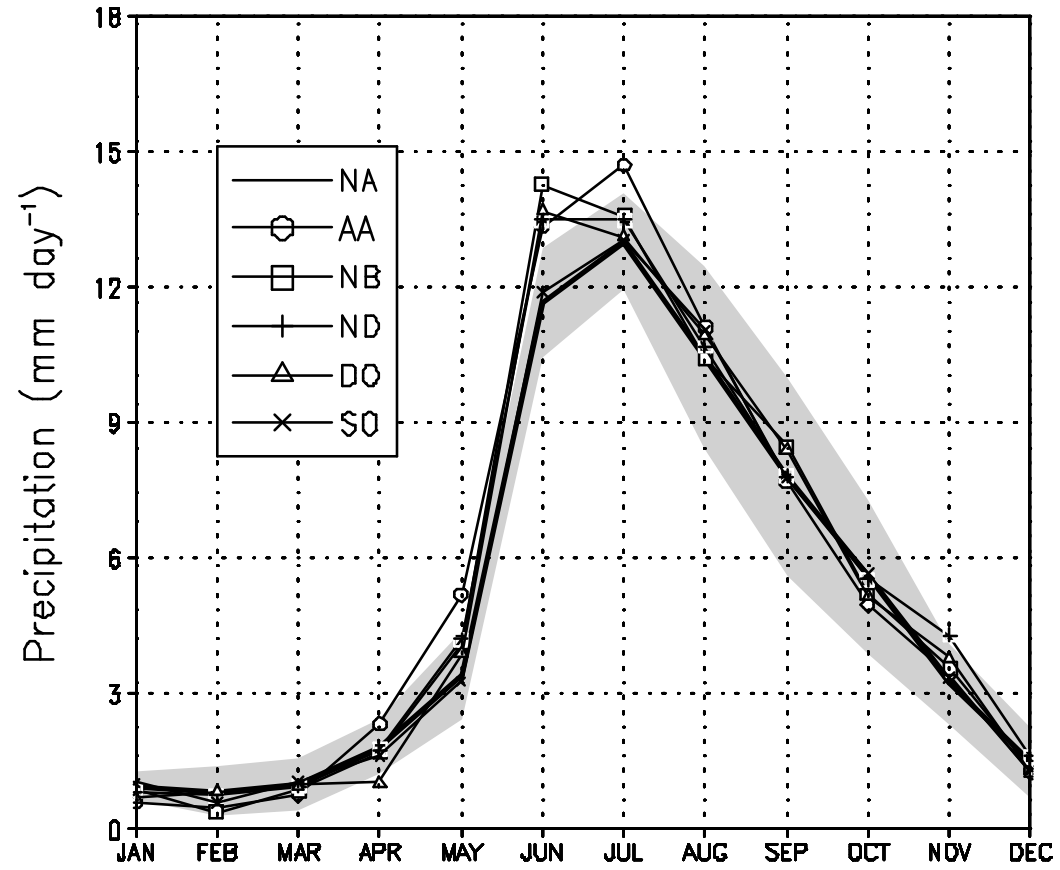

Fig. 8 